\title{
Computer Simulations for Total Firesafety \\ Design of the New Japanese Sumo \\ Wrestling Headquarters \\ and Stadium (Kokugikan)
}

HIROOMI SATO and TOMIO OUCHI

Kajima Institute of Construction Technology, Japan

ABSTRACT

This paper reports the application of total firesafety system consist of simulation programs for fire behaviour, smoke propagation and evacuation behaviour, to the Kokugikan's firesafety design. This building is composed of a large central space with seats for 11,500 spectators.

Assuming that fire occured in the office room and the generated smoke flowed into the large central space, various simulation were conducted.

As a result, it is predicted that the time when smoke will reach to the spectator seats is about 9.5 minutes for 2 nd to 3 rd floors and over 15 minutes for lst floor even if the top rent is shut. On the other hand, from evacuation simulation resuits, 5,000 spectators on the 2 nd to 3 rd floors can arrive at the roor evacuation place about $3-4$ minutes after the start of evacuation, and 6,500 spectators on the lst floor can arrive at outioors about 10 minutes.

Through the comparison of the smoke accumulation speed and evacuation behaviour, it is conirmed that 11,500 spectators can arrive at outdoors without danger from smoke and that there is no necessity to change the original plan.

This building was completed in January, 1985 .

KEY WORDS

Computer simulation, Firesafety design, Fire, Smoke propagation, Evacuation 


\section{INTRODUCTION}

Factors concerning building firesafety are multifarious and include the problem of human safety, so that it is difficult to verify and find "absolute" firesafety by full scale and realistic experiments. Therefore, it is desirable to establish a systematic method for the assesment of "relatively" risk free and rational fire protection measures taking the properties of objective buildings and their occupants into consideration.

So the authors have proposed a total firesafety system by means of computer simulations based on engineering knowledge. 'We considered this system as a time-sequence interaction system composed of six submodels for buizding, fire, smoke propagation, evacuation, information and equipment. We developed several computer simulation programs to calculate the behaviour of fire, smoke, and occupants during every minute of the fire taking account of the other submodels.

This paper reports the application of these simulation programs to the Kokugikan's firesafety design.

\section{OBJECTIVE BUILDENG}

The "Kokugikan" is the new headquarters of the Japanese national sport "Sumo", which was completed in January, 1985 in Tokyo, Japan. The basic plan and section are shown in FIGURES $1-2$. This building as shown in FIGURE $I$ is composed of a large central space with seats for 11,500 spectators and an entrance hall, lobby, office rooms, as well as Sumo-chayas (which are shops supplying drinks and lunch snacks), Sumo-training rooms, and some restaurants. The height of the large central space for spectators is about 40 meters. The area containing spectators' seats is about 4,250 square meters.

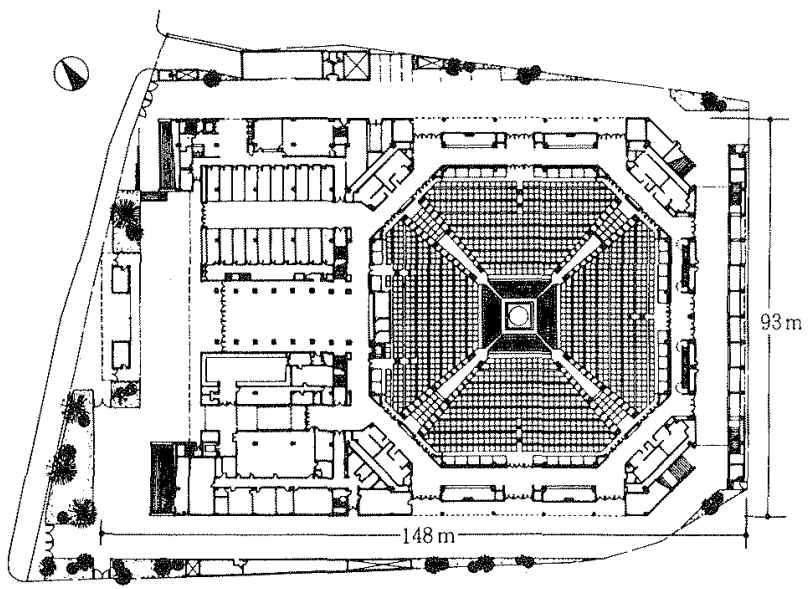

1st Floor

FIGURE 1. Plan 


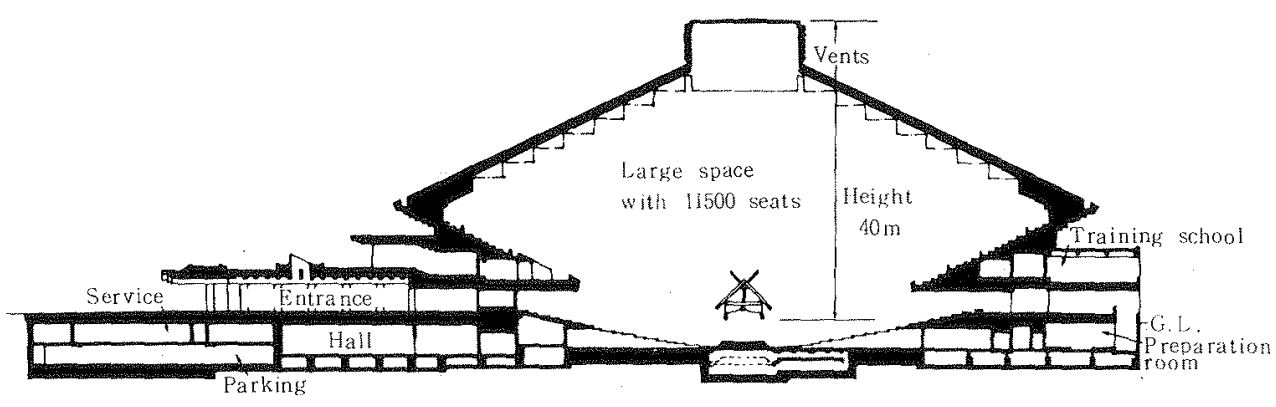

FIGURE 2, Section

\section{POST-FLASHOVER FIRE IN "NIPPON SUMOKYOKAI" OFFICE ROOM}

In the main central space, as the spectators act in a sense as a warning system and also as a fire fighting system so that, even if a fire occurs they can easily detect and extinguish a fire in its early stages. Therefore, the authors supposed it is not necessary to discuss the behaviour of fire in this area. But in rooms such as the office room for Nippon Sumokyokai and the Sumochayas, there is some risk of a fire break out when the staff are out just as there is in the case of any ordinary building. So, in this paragraph, we will discuss the case of a post-flashover fire in the office room.

\section{Simulation Method}

We can calculate post-flashover fire temperature in the compartment by means of the well-known heat balance equation (1) proposed by Dr. Kawagoe et al whereby for any given instant " $t$ " during the course of the fire after flashover.

$$
I_{C}=I_{I}+I_{W}+I_{R}+I_{B}
$$

The treatment on the right side of equation (1) are nearly equal to ones in Kawagoe model.

For the treatment on the left side, the term Ic is given as the product of the burning rate $R(\mathrm{~kg} / \mathrm{hr})$ and the heat of combustion of fuel $Q_{1}(\mathrm{~J} / \mathrm{kg})$, and we assumed that $R$ was based on the type of combustion, and $Q_{1}$ was changed by the incomplete combustion factor.

Here, for $\mathrm{R}$, the assumption was introduced that the fire behaviour in compartment develops either ventilation controlled or fuel controlled combustion, which is determined by the relation between the air supply through the opening of compartment and the necessary air based on the fuel surface area at any fire situation.

Namely, the burning rate at any fire situation $\mathrm{R}$, as shown in dash line in FIGURE 3 , is assumed to be chosen the less of the burning rate at the stage of fuel controlled combustion Rfuel and the burning rate at the stage of ventilation controlled combustion $R_{\text {air. }}$. 


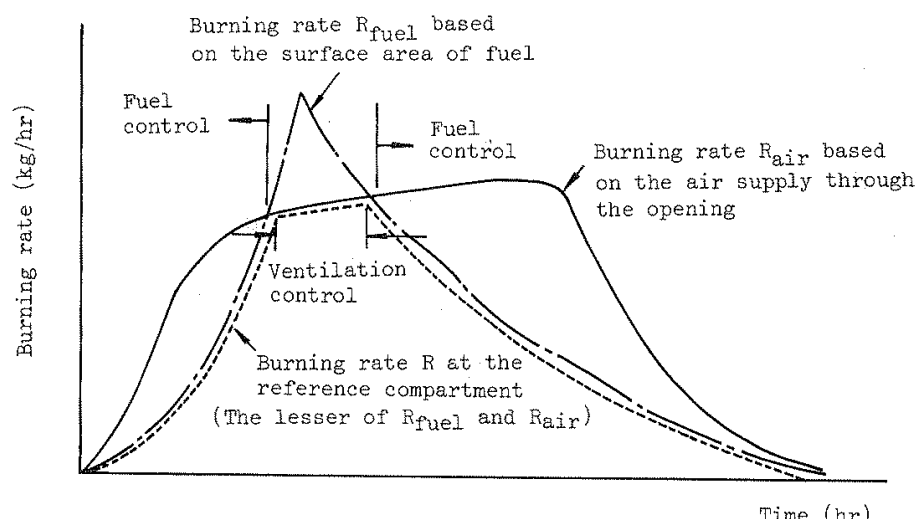

FIGURE 3. Transition model of combustion type

\section{Calculation Results}

From the many survey results which were sponsored or conducted by the Building Research Institute Japan (in 1983), the Society of steel construction of Japan (in 1973), etc, we know that the magnitude of fire loads in offce rooms is in the range of 7 to $53 \mathrm{~kg} / \mathrm{m}^{2}$. So, in this case the magnitude of the fire load of the objective office room was tentatively, considered to be 30 $\mathrm{kg} / \mathrm{m}^{2}$ and though there are various types of combustible material in the office room, the materials are regarded as bejng wooden.

The simulation result is shown in FTGURE 4 . It is seen that the maximum temperature in this room is $810^{\circ} \mathrm{C}$ after 35 minutes.

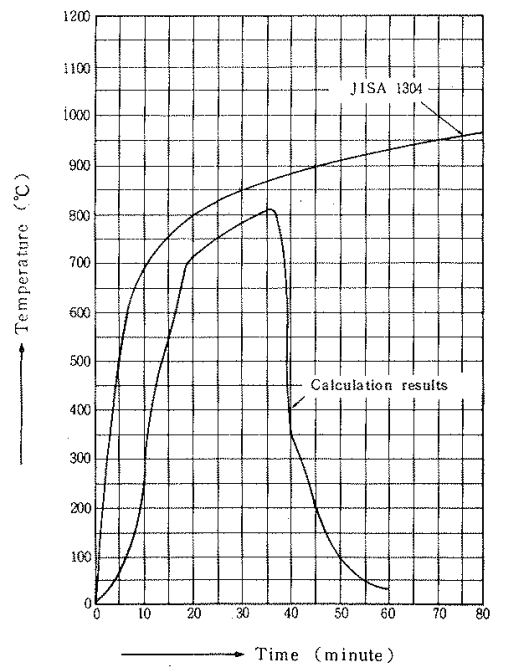
Floor area of the office room $200 \mathrm{~m}^{2}$ opening area $24 m^{2}$ Opening height $3 \mathrm{~m}$ opening width $8 \mathrm{~m}$ Material of cast-in-place Surrounding wall: concrete

Density $\quad 2.1 \mathrm{t} / \mathrm{m}^{3}$ (absolutely ary)
Thickness $12 \mathrm{~cm}$

Thermal conductivity $1.26 \mathrm{~W} / \mathrm{m} . \mathrm{K}$ Specific heat $0.88 \times 10^{3} \mathrm{~J} / \mathrm{kg} \cdot \mathrm{K}$

Moisture content $7 \%$

FIGURE 4. Post-flashover fire temperature in tne objective office room 
Though the smoke generated by combustion in the above mentioned office room fire may be released to all places around the room from its openings it is assumed that all of smoke released flow into the neighboring large central space. In order to estimate smoke accumulation speed in the top of the space, we enlarged and applied Dr. Tanaka's theory ${ }^{3}$ as follows.

\section{Simulation Method}

Simulation model takes into consideration the concept of the roof inclination and heat loss throuth the roof.

The temperature of layer gases $\mathrm{Ts}$ is give by

$$
\frac{d T S}{d t}=\frac{T_{S}}{C_{p} r_{0} T_{0} V_{2}}\left[Q-C_{p} M_{2}\left(T_{S}-T_{0}\right)\right]
$$

Where $Q_{0}=Q_{f}-Q_{L}$

The depth of a layer $Z_{s}$ is given by substituting $V_{2}$ obtained from equation (3) into the ralation between height $\mathrm{z}\left(=\mathrm{z}_{1}+\mathrm{zs}\right)$ and volume $\mathrm{v}\left(=\mathrm{v}_{1}+\mathrm{v}_{2}\right)$. Here the actual roof inclination is considered.

$$
\frac{d V_{2}}{d t}=\frac{Q}{C_{p} \gamma_{0} T_{0}}+\frac{M_{2} T_{Q}-G_{S} T_{S}}{\gamma_{O} T_{0}}
$$

While the mass balance in a lower region is,

$$
\frac{Q}{C_{p} T_{0}}-\frac{T_{S}}{T_{0}} G_{S}+\left(G_{0}+M_{1}\right)=0
$$

Where $G_{S}$ and $G_{0}$ given by pressure $P$ of a room at its floor must satisfy the requirement of the equation (4).

With regard to the plume mass flow, Tsufimoto's equation based on Yih's was applied. Namely, the plume mass flow rate $M_{1}$ and mass flow rate at a hot layer $\mathrm{M}_{2}$ are given as follows.

$$
\begin{aligned}
& M_{1}=0.153\left(\frac{\gamma_{0}^{2} g Q}{C_{p} T_{0}}\right)^{1 / 3} z_{0}{ }^{5 / 3}\left(I+m \frac{\Delta T}{T_{0}}\right)^{-2 / 3} \\
& M_{2}=0.153\left(\frac{\gamma_{0}^{2} g Q}{C_{p} T_{0}}\right)^{1 / 3}\left(z_{0}+z_{1}\right)^{5 / 3}\left(I+m \frac{\Delta T}{T_{0}}\right)^{-2 / 3}
\end{aligned}
$$

While $\Delta \mathrm{T} / \mathrm{T}_{0}$ in the height $\mathrm{Z}^{\prime}$ is,

$$
\begin{aligned}
& \Delta T_{T} / T_{0}=3(I-3 F)+\sqrt{(I-3 F)^{2}+I} \\
& I / F=11.0 \times\left(\frac{Q}{\gamma \circ C_{p} T_{0}}\right)^{1 / 3} \cdot g^{-1 / 3} Z^{-5 / 3}
\end{aligned}
$$

Fúrther $G_{0}$ and $G_{S}$ are calculated by general ventilation calculation methoo..

\section{Calculation Results}

By means of solving above-mentioned simultaneous equations (2) to (8) etc. in any given instant, "t", we got the smoke accumulation speed in the large space. 
The conditions in this calculation are as follows.

(a) As mentioned above, it is assumed that all of smoke released flows into the large central space. So, from the result of fire simulation, $Q_{f}$ is given as time-function. The area of fire source at the ground level is regarded as $3 \times 3 \mathrm{~m}$ taking account of the area of objective door opening in this large central space. Therefore, the height of the virtual point source is regarded as $4.5 \mathrm{~m}$ beneath the standard floor level +6.0 meter.

(b) Temperature of ambient air is $22^{\circ} \mathrm{C}$ with no wina.

(c) Except doors facing to a fire room, it is supposed that all doors in this space are kept open for the purpose of evacuation. So, neutral height of openings is $3.5 \mathrm{~m}$, and effective area of inlet air $\alpha i A i$ is $140 \mathrm{~m}^{2} .(\alpha i=$ $0.65)$

(d) Actual top vent area $A_{s}$ is $177 \mathrm{~m}^{2}$ and $\alpha$ s is regarded as 0.4 taking account of the efficiency of louver, therefore $\alpha_{S} A_{S}=70.8 \mathrm{~m}^{2}$. Distance from the standald floor level (G.L.-4.0 meter) to the vent is $36.8 \mathrm{~m}$.

For comparison with the above conditions, the cases of $\alpha$ sAs $=0$ and $\alpha$ sAs $=$ $35.4 \mathrm{~m}^{2}$ were calculated. Calculated results are, shown in FIGURE 5 . It is seen that the depth of a layer $\mathrm{z}_{\mathrm{S}}$ is about $13 \mathrm{~m}$ at 10 minutes after ignition if the top vent is kept open.

\section{EVACUATION BEHAVIOUR FROM THE LARGE CENTRAL SPACE}

When the staff failed to extinguish the above-mentioned fire and the smoke began to flow into the central space, the Il, 500 spectators need to move to protect their lives to the safest area, $\dot{i} . e$. out-of-doors. In this paragraph, we discuss how many minutes it takes for 11,500 spectators to arrive out of doors by way of the prescribed evacuation route and whether there is any interference on evacuation behaviour or not.

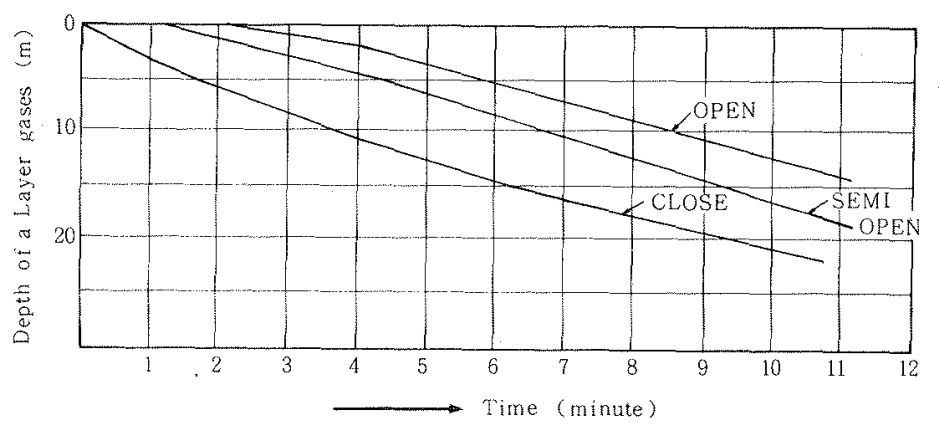

FIGURE 5. Smoke accumulation speed in the large space (calculation results) 
Simulation model is constructed using the investigation results and calculation results for 9,000 spectators behaviour watching sumo wrestling matches at the Osaka-prefectural gymnasium as follows.

Evacuation route and its zoning. We divided this building into small blocks in accordance with evacuation route, such as chairs, box seats (usually 4 persons per one box seat), passage, lobby, corridor, staircase and out-door salety area. We considered each block to be a branch, and supposed a network structure, as shown in FIGURE 6 to be composed of branches. It is supposed that 2 to 5 boxseats and 3 to 28 chairs are respectively regarded as the unit evacuation zone, and use the same passage. The zonings of passage blocks were carefully zoned taking account of the existence of junctions and the divergence.

As concerns junctions, if the lower part is not wide enough for the evacuation behaviour, it is assumed that the ratio of junction number is proportional to the width of each part of the upper stream. The ratio of the divergence numberis also proportional to the width of the lower part.

Spectators' walking speed and capacity of each branch. The relations between the walking speed and crowd density using in this model are shown in FIGURE 7, which are based on the past imvestigations. 194 And the distribution of evacuation start time is shown in FIGURE 8. Here, as for box seats, this aistribution was obtained from the investigation results at the osaka-prefectural gymasium. For chairs, the distribution was asumed as FIGURE 8 (b) in consideration of investigation results.

Passing time of each branch is based on the length of each branch and evacuee's walking speed (based on FIUGRE 7) in each brance. As concerns the capacity of each branch, it is supposed that in the lobby it is 3.0 persons $/ \mathrm{m}^{2}$ and in passages 3.5 persons $/ \mathrm{m}^{2}$. (In narrow lateral passages, 1 person $/ 50 \mathrm{~cm}$ )

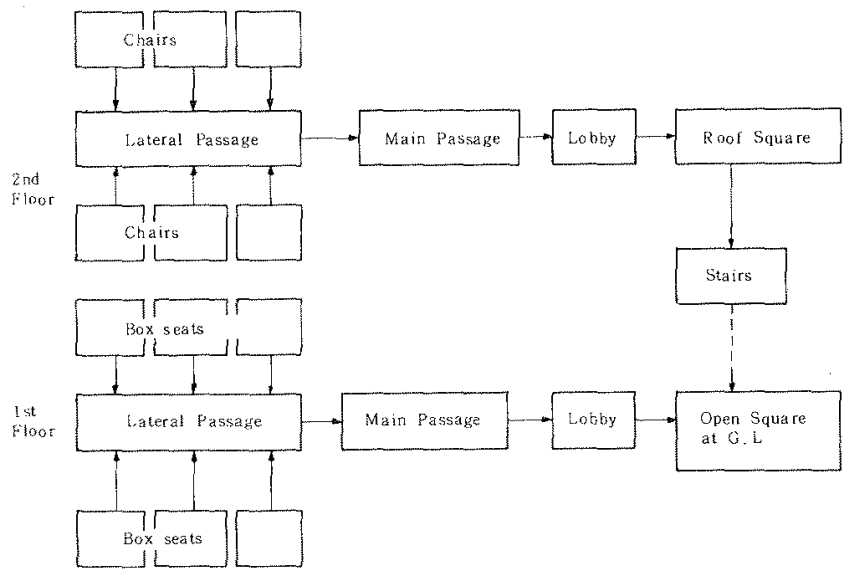

FIGURE 6. Block diagram of evacuation route 


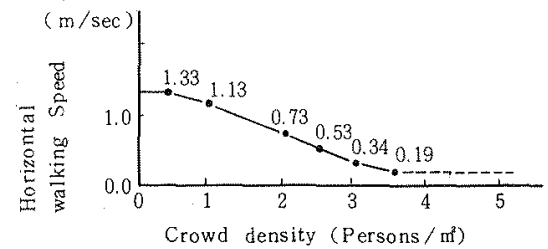

(a) Passages

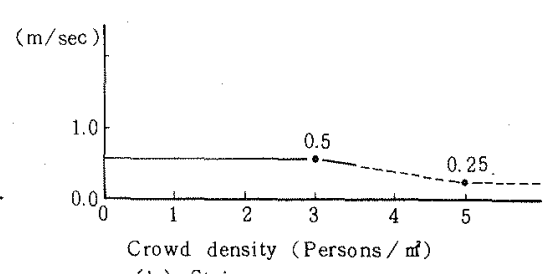

(b) Stairs

FIGURE 7. Relation between the horizontal walking speed and crowd density

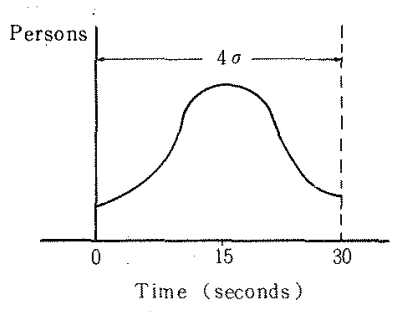

(a) Box seats

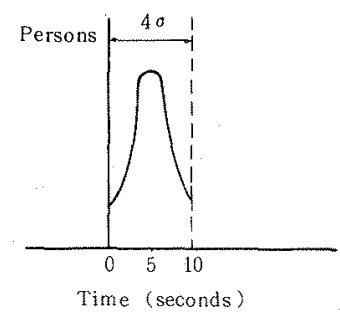

(b) chairs

FIGURE 8. Distribution on time of evacuation start

Calculation Reselts

We calculated the case where it is impossible to use one of the main passages on the lst floor for evacuation as a result of the office room fire.

Examples of the calculation results are shown in FIUGRE 9. Namely, it is seen that 6,500 spectators on the Ist floor could arrive out-of-doors $593 \mathrm{sec}-$ onds after the start of the evacuation, and 5,000 spectators on the 2nd to 3rd floors could arrive at the roof evacuation place in 208 seconds. We made sure that was no interference on their evacuation route.

Therefore, from FIGURE 5 and FIGURE 9, we can confirm that even if all of smoke generated by the neighbouring office room fire flows into the large central space and even if the top vent is shut, 11,500 spectators can arrive safety out of door without danger from the smoke.

\section{SUMMARY}

In this paper, we have reported on the application of a total firesafety system composed of simulation system of fire behaviour, smoke propagation, and evacuation behaviour to the Kokugikan's firesafety design.

We calculated the post-flashover temperature in the office room which is the most risky in case of an outbreak of fire in this building, and the smoke accumulation speed in the large central space according to the heat energy withdrawn from the room during the fire.

Finally, we discussed how fast 11,500 spectators can arrive out-of-doors by way of the prescribed evacuation routes. Through comparison of the smoke accumulation speed and evacuation behaviour during every minute, we confirmed that there was no necessity to change the criginal plan. 

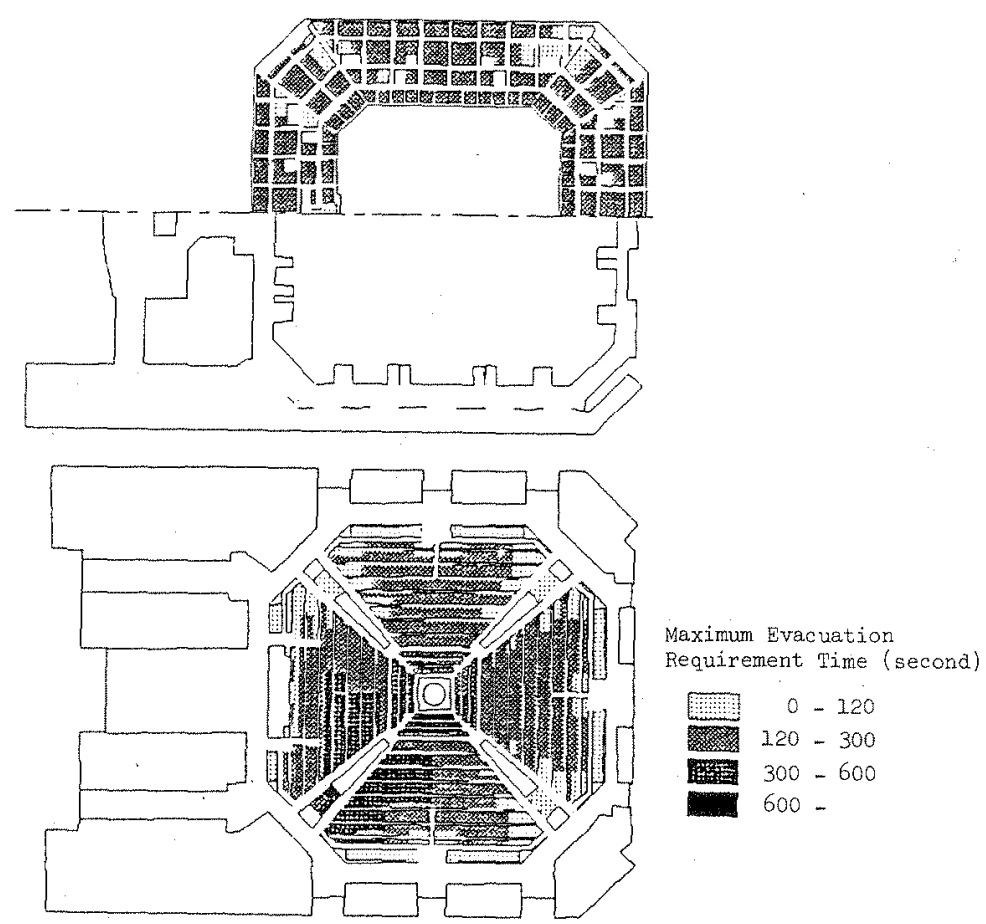

FIGURE 9. CaIculation result (maximum evacuation requirement time)

\section{ACKNOWLEDGEMENTS}

This research was conducted by the Firesafety Systems Development Group of Kajima Corporation. The members of group except authors are M.Nagatomo Dr. Eng., K.Muta Dr.Eng., S.Hayakawa, S.Togari, K.Kageyama, K.Nakazawa, Y.Hara, H.Kurioka, Y.Sassa et al. The assistance of "Nippon Sumo Kyokai (Japan Sumo Association)" that permitted the presentation of this paper is gratefully acknowledged.

\section{REFEPENCES}

I. K. Muta. H. Sato et al; "Study on a Total Fire Safety System", CIB Symposium, System Approach to Fire Safety in Buildings, Tsukuba, Japan, 29 and 30 August, 1979.

2 H. Sato et al; "Surrounding Materials and Fire Behavior (No.1 to 4)", Architectural Institute of Japan Annual Meeting Abstract Report, Fire Division, $1976,1977,1979,1980$. (In Japanese).

3. T. Tanaka; "Discussion on Modeling of Pre-flashover Behavior" Japanese Association of Fire Science and Engineering Annual Meeting Reports, 1976 etc. (In Japanes).

4. J.J. Fruin; Hokosha no Kukan, Translated into Japanese by M. Nagashima, Kajima Inst. Pub. Co., 1974, Original Title; PRDSTRIAL Planning and Design, 1971 . 
Af Area of virtual fire source $\left(\mathrm{m}^{2}\right)$

$A_{i} \quad$ Area of inlet $\operatorname{air}\left(\mathrm{m}^{2}\right)$

As Area of vent (outlet gases) $\left(\mathrm{m}^{2}\right)$

$\mathrm{C}_{\mathrm{p}} \quad$ Specific heat $(\mathrm{J} / \mathrm{Kg} \cdot \mathrm{K})$

$g$ Acceleration due to gravity $\left(\mathrm{cm} / \mathrm{s}^{2}\right)$

$\mathrm{G}_{0}$ Mass inflon rate $(\mathrm{Kg} / \mathrm{s})$

$\mathrm{G}_{\mathrm{S}}$ Mass outflow rate through vent $(\mathrm{Kg} / \mathrm{s})$

$I_{B}$ Heat energy stored per unit time in the gas volume contained in the compartment (W)

IC Heat energy released per unit time during combustion (W)

I $\quad$ Heat energy withdrawn per unit time from the compartment owing to the replacement of hot gases by cold air (W)

$I_{R} \quad$ Heat energy withdrawn per unit time from the compartment by radiation through the openings (W)

I W Heat energy withdrawn per unit time from the compartment through wall, roof or ceiling etc. (W)

m $\Delta \mathrm{m} / \Delta \mathrm{T}=0.5$ (regarded to Gauss distribution)

$\mathrm{Me} \quad$ Mass flow rate of entrained gas ( $\mathrm{Kg} / \mathrm{s})$

$M_{1}$ Mass flow rate in fire plume $(\mathrm{Kg} / \mathrm{s})$

$\mathrm{M} 2$ Mass flow rate at a hot layer $(\mathrm{Kg} / \mathrm{s})$

$P$ Pressure of a room at its floor (Pa)

Q Qf - QI, (W)

$Q_{f}$ Heat release rate of combustion of fuel (W)

QT Heat loss through the roof (W)

Q1 Heat of combustion of fuel ( $\mathrm{J} / \mathrm{Kg}$ )

$\mathrm{R}$. Burning rate ( $\mathrm{Kg} / \mathrm{hr}$ )

$R_{a i r}$ Burning rate at the stage of ventilation controlled combustion ( $\mathrm{Kg} / \mathrm{hr}$ )

Rfuel Burning rate at the stage of fuel controlied combustion ( $\mathrm{Kg} / \mathrm{hr}$ )

$\mathrm{S}_{\mathrm{A}}$ Surface area of wood crib $\left(\mathrm{m}^{2}\right)$

$S_{A S}$ opening area at bottom of wood $\mathrm{crib}\left(\mathrm{m}^{2}\right)$

$T_{0} \quad$ Temperature of ambient air (K)

$\mathrm{T}_{\mathrm{S}}$ Temperature of layer gases $(K)$

$\Delta \mathrm{T}$ Temperature rise at the center of any plume section $\left({ }^{\circ} \mathrm{C}\right)$

$\Delta \mathrm{T}_{\mathrm{m}} \quad$ Mean temperature rise at above section $\left({ }^{\circ} \mathrm{C}\right)$

$\mathrm{TM}_{\mathrm{M}}$ Time of maximum rate of combustion ( $\mathrm{hr}$ )

$V_{1} \quad$ Volume of ambient air $\left(\mathrm{m}^{3}\right)$

$\mathrm{V}_{2}$ Volume of layer gases $\left(\mathrm{m}^{3}\right)$

$\mathrm{Z}$ Distance from floor to vent $(\mathrm{m})$

$z^{-} \quad z_{0}+z_{1}(m)$

$Z_{0}$ Distance from virtual point source to floor $(\mathrm{m})$

$Z_{1} \quad$ Distance from floor to layer $(\mathrm{m})$

$z_{\mathrm{S}} \quad$ Depth of layer $(\mathrm{m})$

$\alpha \dot{i}$ Effective coefficient for area of inlet air

$\alpha_{S}$ Effective coefficient for area of outlet air

Yo Density of ambient air $\left(\mathrm{Kg} / \mathrm{m}^{3}\right)$

$\gamma_{\mathrm{s}}$ Density of layer gases $\left(\mathrm{Kg} / \mathrm{m}^{3}\right)$ 